\title{
Maternal delays in utilizing institutional delivery services, Bahir Dar, Ethiopia
}

\author{
Worku Awoke $^{1^{\star}}$, Kenie Seleshi ${ }^{2}$ \\ ${ }^{1}$ College of Medicine and Health Sciences, Bahir Dar University, Bahir Dar, Ethiopia; \\ *Corresponding Author: Workuawo@yahoo.com \\ ${ }^{2}$ GAMBY College of Medical Sciences, Bahir Dar, Ethiopia
}

Received 16 April 2013; revised 17 May 2013; accepted 4 June 2013

Copyright (C) 2013 Worku Awoke, Kenie Seleshi. This is an open access article distributed under the Creative Commons Attribution License, which permits unrestricted use, distribution, and reproduction in any medium, provided the original work is properly cited.

\section{ABSTRACT}

Introduction: Timely referrals and access to appropriate health care had a great impact on reduction to maternal deaths and disabilities. Maternal delay is one of the contributing factors for high maternal mortality in developing countries. Maternal delays were categorized into three levels: delay in making the decision for seeking care, delay in arrival at a health facility, and delay in receiving adequate treatment. They have been named first, second, and third delay maternal delays; respectively. This study was aimed at assessing maternal delays in utilizing institutional delivery service sin Bahir Dar, North-Western Ethiopia. Methods: A cross sectional facility based study was conducted on a sample of 422 women attending at a public health facility for delivery services. The sample size was determined by using single population proportion formula and the study participants were selected by using a systematic random sampling method. Data were collected by means of a pre-tested, standardized questionnaire; analysis was carried out using SPSS version 16 . Results: Data was collected from 410 laboring mothers. First delay, 155 (37.8\%) of mothers was delayed in decision making for seeking care from the public health facility and the mean delay was 8 hours. Delay in seeking emergency obstetric care [EOC] was about seven fold among illiterate mothers (AOR, 6.71; 95\% Cl, 3.66 12.29) than literate mothers; the odds of delay for EOC were three times more likely among mother were unable to make decisions by their own (AOR, 3.30; 95\%Cl, 1.25 - 7.20) than those mothers who made the decisions of their own. Unemployed mothers were 4 times more likely to have the maternal delay in seeking EOC (AOR, $3.94 ; 95 \% \mathrm{Cl}, 2.36$ - 6.57) than employed mothers. Second delay, 130 (31.7\%) of mothers had transportation problems in reaching health care facilities. Predictors in the first maternal delay were also the major contributing factors for this delay. The third delay, after their arrival at health facilities, $126(30.7 \%)$ mothers reported that they did not get the services on time; the mean waiting time for getting the service was 4 hours. Conclusions: Many mothers were not getting institutional delivery care services in a timely manner, due to the "three maternal delays". Mothers' literacy, decision making power and employment status were the main predictors for delivery service utilization. Hence, emphasis should be given for awareness creation on the risks of maternal delays, designing income generating mechanism, women empowering for in decision making and ambulance services should be strengthened.

Keywords: Maternal Delays; Delivery Service; Ethiopia

\section{INTRODUCTION}

All pregnant women are at risk of obstetric complications [1]. Every day, 800 women die from pregnancyrelated causes during pregnancy, childbirth and postpartum. Over $99 \%$ of these 287,000 annual deaths occur in developing countries [2]. Most maternal deaths due to pregnancy and child birth related complications are unpredictable; however, it is preventable by timely referrals to emergency obstetric care service [3]. Maternal delay in utilization of emergency obstetric care is one of the contributing factors for high maternal mortality in developing countries [4]. Maternal delays were described 
as having three levels: delay in making decision to seek care, delay in arrival at a health facility, and delay in receiving adequate treatment, which have been named first, second, and third delay maternal delays respectively [5, $6]$.

Improving maternal health is one of the millennium development goals with a target of reducing the maternal mortality ratio by three-quarters over the period 1990 to 2015 [7].

In Ethiopia, Maternal deaths account for 30 percent of all deaths to women age 15 - 49 and maternal mortality ratio was estimated to 676 maternal deaths per 100,000 live births [8].

Maternal deaths can be minimized by using known effective interventions, such as skilled birth attendance and provision of comprehensive emergency obstetrical care [9]. Mothers in developing countries had lower chance for accessing emergency obstetric care due to socio-economic, social, cultural, female decision making power, ignorance, distance, transportation and political constraints [1015].

This study was conducted to assess the three maternal delays for utilization of emergency obstetric care and its associated factors among women attending public health facility in Bahir Dar, North-West Ethiopia. 2012.

\section{METHODS}

\subsection{Study Design}

Cross-sectional study was conducted among mothers attending at public health facilities in Bahir Dar City, Ethiopia from January to February 2012. Bahir Dar is the capital city of Amhara National Regional State; located at the geographical coordinates of $11^{\circ} 38^{\prime}$ north latitudes and $37^{\circ} 15^{\prime}$ east longitudes.

The sample size was determined by using a single population proportion formula, which took the proportion of mothers having maternal delays 50\% (this figure was used since there was no any other study in study area) with a margin of error of $0.05 \%$ at the $95 \%$ confidence interval (CI); Then adding a 10\% non-response rate, the final sample size was calculated to be 422 . The respondents were selected by using systematic sampling method from each public health facilities.

\subsection{Data Collection and Data Analysis}

A structured questionnaire was prepared in English before being translated into the local language (Amharic) and then back-translated into English. Sections that showed any discrepancies underwent revision. Four Nurses for data collection and two supervisors were recruited, and training was given; this mainly dealt with the purpose of the study, handling ethical issues and method of data collection. The questionnaire was pre- tested prior to data collection and corrections were made accordingly. For consistency and completeness, the collected data were checked in a daily basis by supervisors. The collected data were coded, entered, cleaned, and analyzed using statistical package of SPSS version 16. Bivariate analysis was conducted to examine the various associations using the chi-square test. In addition, crude and adjusted odds ratios (ORs) and 95\% confidence intervals (CI) were calculated after the chi-square test to test the strength of association and level of significance; respectively. $\mathrm{p}$-value $\leq 0.05$ was considered statistically significant.

\subsection{Ethical Considerations}

The research topic and methodology were approved by ethical committee of Bahir Dar University and GAMBY College of Medical Sciences. Permission to conduct the study was also obtained from Amhara Regional State Health Bureau and Bahir Dar Health Office. During data collection, the purpose of the study was clearly explained to the study participants, and informed oral consent was obtained. Participants were assured of confidentiality with regard to all information acquired and told that they had the right to withdraw from the study at any time during the interviewing.

\section{RESULTS}

\subsection{Socio-Demographic Characteristics of the Respondents}

In all, 422 laboring mothers were asked to be participant of this study and 410 of them gave their oral consents and interviewed, yielding a response rate $97.6 \%$. Of the respondents, $286(69.8 \%)$ were found within the age range of 20 - 34 years, $390(95.1 \%)$ were married and 257 (62.7\%) were illiterate. The majority, 391 (95.4\%) were Amhara in ethnicity, 344 (83.9\%) were Orthodox Christians and 240 (58.5\%) were unemployed. The mean family income was calculated to be 1390 Ethiopian Birr per month (1 USD was equivalent to 17.5 Ethiopian Birr (ETB) (Table 1).

\subsection{The First Maternal Delay (Delay in Seeking Care) and Its Determinants}

Of the total study participants, 155 (37.8\%) of them reported that they faced problem on making decision to seek emergency obstetric care from health facilities. The mean delay time was 8 hours with a range of 1 hour to 48 hours. The bivariate analysis showed that there was a statistically significant association between having knowledge about antenatal care, age, educational status, occupation, monthly income, consultation, decision making power, preference of place of delivery; problems 
Table 1. Socio-demographic characteristics of mothers, 2012. $(\mathrm{n}=410)$.

\begin{tabular}{|c|c|c|c|}
\hline \multicolumn{2}{|c|}{ Variables } & \multirow{2}{*}{$\begin{array}{c}\text { Frequency } \\
71\end{array}$} & \multirow{2}{*}{$\begin{array}{c}\text { Percent } \\
17.3\end{array}$} \\
\hline \multirow{3}{*}{ Age in years } & $15-19$ & & \\
\hline & $20-34$ & 286 & 69.8 \\
\hline & Above 35 & 53 & 12.9 \\
\hline \multirow{3}{*}{ Marital status } & Married & 390 & 95.1 \\
\hline & Single & 14 & 3.4 \\
\hline & Divorce & 6 & 1.5 \\
\hline \multirow{2}{*}{ Educational status } & Literate & 153 & 37.3 \\
\hline & Illiterate & 257 & 62.7 \\
\hline \multirow{4}{*}{ Ethnicity } & Amhara & 391 & 95.4 \\
\hline & Tigerie & 10 & 2.4 \\
\hline & Agaw & 8 & 2 \\
\hline & Oromo & 1 & 0.2 \\
\hline \multirow{2}{*}{ Occupation } & Employed & 170 & 58.5 \\
\hline & Unemployed & 240 & 41.5 \\
\hline \multirow{3}{*}{ Income (ETB) } & $\geq 2000$ & 97 & 23.7 \\
\hline & $1001-1999$ & 91 & 22.2 \\
\hline & $\leq 1000$ & 222 & 54.1 \\
\hline \multirow{3}{*}{ Religion } & Orthodox & 344 & 83.9 \\
\hline & Muslim & 59 & 14.4 \\
\hline & Protestant & 7 & 1.7 \\
\hline
\end{tabular}

in previous and current pregnancy with delay in seeking emergency obstetric care at $p$-values $\leq 0.05$ (Table 2).

Adjustment of variables using logistic regression was carried out to predict the first maternal delay in seeking emergency obstetric care with associated variables during the crude analysis. Maternal delay in seeking EOC was 3.94 times higher among unemployed mother (AOR, 3.94; 95\%CI, 2.36 - 6.57) than employed ones; was 6.71 fold higher in illiterate mothers (AOR, 6.71; 95\%CI, 3.66 - 12.29) than literate mothers. Delay in seeking EOC was 2.75 times higher among mothers whose monthly income below 1000.00 ETB (AOR, 2.75; 95\%CI, 1.347 - 5.644) than whose monthly income 2000.00 ETB and above. Mother who had been influenced by her husband was 2.19 times higher in having delay (AOR, 2.19; 95\%CI, 1.25 - 3.85) than mothers who made decisions by their own. The odds of delay in seeking EOC was 4.51 times higher among mothers who had not ANC follow up (OR, 4.51; 95\%CI, 2.45 - 8.30) than mothers who had ANC follow up during their pregnancy (Table 2).

\subsection{The Second Maternal Delay (Delay Due to Transportation) and Its Determinants}

Of 422 mothers, $130(31.7 \%)$ mothers reported that they faced transportation problem to the health institutions for getting emergency obstetric services and they went a minimum three hours walking distance to reach the health care facilities. As to the means of transportations, $219(53.5 \%)$ mothers were traveled by care, 74 $(18 \%)$ of mothers were carried by wooden stretcher and the remaining 117 (28.5\%) were on foot (Table 3).

To predict the second maternal delay for utilization emergency obstetric care, variables which showed a significant statistical association with p-value less than or equal to $50 \%$ was adjusted using logistic regression. The result showed that unemployed mothers were 2.52 time higher in having the second maternal delays (AOR, 2.52; $95 \%$ CI, 1.55 - 4.11) than employed mothers; illiterate mothers were 4.27 fold higher in having the second maternal delays (AOR, 4.27; 95\%CI, 2.65 - 6.90) than literate mothers. Delay due to transportation was 4.86 times higher among mothers whose monthly income below 1000.00 ETB (AOR, 4.86; 95\%CI, 2.62 - 9.01) than whose monthly income 2000.00 ETB and above (Table 4).

\subsection{The Third Maternal Delay (Delay at Health Facility Level) and Its Determinants}

After their arrivals' at health facilities, 126 (30.7\%) mothers reported that they did not get timely the emergency obstetric care. The mean delay time was 4 hours. With regard to problems at health facility, 49 (12\%) mothers reported as long time admission process, 44 (10.3\%) lack of supplies and $32(7.8 \%)$ and staff work load were reasons delays at health facility level. Logistic regression was computed for socio demographic variables, means of delivery with facility delays. None of the socio demographic variables showed statistically significant. However mothers who were not delivered with spontaneous vaginal delivery (caesarian section, instrumental delivery and induced labor) were about two times more likely having maternal delay at facility level (AOR, 1.66; 95\%CI, $1.03-2.68$ ) than those mothers who delivered in spontaneous vaginal delivery (Table 5).

\section{DISCUSSIONS}

The findings of this study show that 155 (37.8\%) of mothers had the first maternal delay in deciding to seek emergency obstetric care; this figure is lower than that reported in a study done rural Bangladesh, $69.3 \%$ perceived delay in deciding to seek care [4]. However, the mean delay to make a decision was 8 hours; this figure is higher than the study findings in rural Bangladesh, time required to make a decision to seek care was reported 72 minutes [4]. In this study, literacy status of mothers, decision making power and employment status were the 
Table 2. Maternal delays at household level and associated factors, $2012(n=410)$.

\begin{tabular}{|c|c|c|c|c|c|}
\hline \multirow{2}{*}{\multicolumn{2}{|c|}{ Variables }} & \multicolumn{2}{|c|}{ Maternal delay } & \multirow{2}{*}{ COR } & \multirow{2}{*}{ AOR } \\
\hline & & Yes & No & & \\
\hline \multirow{3}{*}{ Age } & $15-19$ & 18 & 53 & 1.0 & 1.0 \\
\hline & $20-34$ & 113 & 173 & $1.92(1.072,3.450)$ & $2.85(1.266,6.447)$ \\
\hline & $35-49$ & 24 & 29 & $2.43(1.139,5.213)$ & $6.0(2.118,17.038)$ \\
\hline \multirow{2}{*}{ Occupation } & Employed & 32 & 138 & 1.0 & 1.0 \\
\hline & Unemployed & 123 & 117 & $4.57(2.88,7.24)$ & $3.94(2.36,6.57)$ \\
\hline \multirow{2}{*}{ Education } & Literate & 32 & 121 & 1.0 & 1.0 \\
\hline & Illiterate & 123 & 134 & $3.43(2.19,5.49)$ & $6.71(3.66,12.29)$ \\
\hline \multirow{3}{*}{ Monthly income } & $>2000$ & 25 & 72 & 1.0 & 1.0 \\
\hline & $1001-1999$ & 38 & 53 & $2.06(1.11,3.82)$ & $1.89(0.83,4.30)$ \\
\hline & $<1000$ & 92 & 130 & $2.03(1.20,3.45)$ & $2.75(1.34,5.64)$ \\
\hline \multirow{2}{*}{ Problem in previous pregnancy } & Problem & 10 & 59 & 1.0 & 1.0 \\
\hline & No problem & 145 & 196 & $4.36(2.159,8.823)$ & $4.16(1.696,10.247)$ \\
\hline \multirow{3}{*}{ Decision maker for EOC } & Women & 28 & 114 & 1.0 & 1.0 \\
\hline & Husband & 91 & 121 & $3.06(1.86,5.02)$ & $2.19(1.25,3.85)$ \\
\hline & Family & 36 & 20 & $7.38(3.69,14.54)$ & $3.30(1.52,7.20)$ \\
\hline \multirow{3}{*}{ Who consulted about EOC } & Health professional & 63 & 157 & 1.0 & 1.0 \\
\hline & TBA & 12 & 17 & $1.75(0.79,3.89)$ & $1.27(0.50,3.21)$ \\
\hline & Family & 80 & 81 & $2.46(1.60,3.76)$ & $2.11(1.27,3.49$ \\
\hline \multirow{2}{*}{ Problem in current pregnancy } & No problem faced & 34 & 36 & 1.0 & 1.0 \\
\hline & Problem faced & 121 & 219 & $1.70(1.01,2.87)$ & $1.71(0.91,3.22)$ \\
\hline \multirow{2}{*}{ ANC follow up } & Yes & 96 & 220 & 1.0 & 1.0 \\
\hline & No & 59 & 35 & $3.86(2.38,6.25)$ & $4.51(2.45,8.30)$ \\
\hline
\end{tabular}

Table 3. Means of transportation and transportation problems to reach the nearest health facility, $2012(n=410)$.

\begin{tabular}{|c|c|c|c|}
\hline \multicolumn{2}{|c|}{ Variables } & \multirow{2}{*}{$\begin{array}{c}\text { Frequency } \\
130\end{array}$} & \multirow{2}{*}{$\begin{array}{r}\text { Percent } \\
31.7\end{array}$} \\
\hline Transportation & Yes & & \\
\hline problem & No & 280 & 68.3 \\
\hline & $\leq 3$ hours & 280 & 68.3 \\
\hline \multirow{2}{*}{$\begin{array}{l}\text { Walking time from } \\
\text { home to health facility }\end{array}$} & $>3$ hours & 130 & 31.7 \\
\hline & Car & 219 & 53 \\
\hline \multirow{2}{*}{$\begin{array}{c}\text { Means of } \\
\text { transportation }\end{array}$} & Wooden stretcher & 74 & 18 \\
\hline & On foot & 117 & 29 \\
\hline
\end{tabular}

main predictors for maternal delays in deciding to seek emergency obstetric care. Similar the role of gender in seeking emergency obstetric care was reported a study done in 2009 at urban slums in Bangladesh [16].

With regard to maternal delay due to transportation, $130(31.7 \%)$ mothers reported that they faced transportation problem to reach the health institutions for getting emergency obstetric services. In this study employment, literacy status of mothers and monthly income were the main predictors for maternal delay due to transportation.
Table 4. Factors associated with maternal delays due to transportation, $2012(\mathrm{n}=410)$.

\begin{tabular}{|c|c|c|c|c|}
\hline \multirow[t]{2}{*}{ Variables } & \multicolumn{2}{|c|}{$\begin{array}{l}\text { Delay due to } \\
\text { transportation }\end{array}$} & \multirow[t]{2}{*}{$\begin{array}{l}\text { Crude odds } \\
\text { ratio }(95 \% \mathrm{CI})\end{array}$} & \multirow[t]{2}{*}{$\begin{array}{l}\text { Adjusted odds } \\
\text { ratio }(95 \% \mathrm{CI})\end{array}$} \\
\hline & Yes & No & & \\
\hline \multicolumn{5}{|l|}{ Occupation } \\
\hline Un employed & 94 & 134 & 1.0 & 1.0 \\
\hline Employed & 36 & 146 & $2.39(1.52,3.75)$ & $2.52(1.55,4.1)$ \\
\hline \multicolumn{5}{|l|}{ Education } \\
\hline Literate & 75 & 78 & 1.0 & 1.0 \\
\hline Illiterate & 55 & 202 & $3.53(2.21,5.28)$ & $4.27(2.65,6.9)$ \\
\hline \multicolumn{5}{|c|}{ Monthly income (ETB) } \\
\hline$\geq 2000$ & 19 & 78 & 1.0 & 1.0 \\
\hline $1001-1999$ & 30 & 61 & $2.01(1.03,3.92)$ & $2.87(1.33,6.1)$ \\
\hline$\leq 1000$ & 81 & 141 & $2.35(1.33,4.17)$ & $4.86(2.62,9.0)$ \\
\hline
\end{tabular}

This finding is in consistent with the study findings in Nigeria, 2003; the main obstacles to accessing the hospital for emergency obstetric care were lack of money and transportation difficulties [17].

After arrival of the mothers at health facilities, 126 $(30.7 \%)$ reported that they did not get timely. the emergency obstetric care; this figure is higher than that reported in Jordan for the years 2007-2008, delay in hospi- 
Table 5. Maternal delays at health facility level and associated factors, $2012(n=410)$.

\begin{tabular}{|c|c|c|c|c|}
\hline \multirow[t]{2}{*}{ Variable } & \multicolumn{2}{|c|}{ Facility delay } & \multirow{2}{*}{ COR (95\%CI) } & \multirow{2}{*}{ AOR (95\%CI) } \\
\hline & Yes & No & & \\
\hline \multicolumn{5}{|l|}{ Occupation } \\
\hline Un employed & 94 & 134 & 1.0 & 1.0 \\
\hline Employed & 36 & 146 & $1.454(0.939,2.250)$ & $0.764(0.489,1.195)$ \\
\hline \multicolumn{5}{|l|}{ Education } \\
\hline Literate & 75 & 78 & 1.0 & 1.0 \\
\hline Illiterate & 55 & 202 & $1.22(0.787,1.893)$ & $1.28(0.807,2.016)$ \\
\hline \multicolumn{5}{|c|}{ Monthly income (ETB) } \\
\hline$\geq 2000$ & 19 & 78 & 1.0 & 1.0 \\
\hline $1001-1999$ & 30 & 61 & $1.28(0.681,2.393)$ & $1.213(0.633,2.322)$ \\
\hline$\leq 1000$ & 81 & 141 & $1.28(0.755,2.182)$ & $1.263(0.724,2.203)$ \\
\hline \multicolumn{5}{|c|}{ Means of delivery } \\
\hline SVD & 75 & 222 & 1.0 & 1.0 \\
\hline NSVD & 51 & 62 & $2.435(1.547,3.833)$ & $1.66(1.03,2.68)$ \\
\hline
\end{tabular}

tal care was $17.1 \%$ [13]. The mean delay hour in health facility was calculated to be 4 hours.

With regard to problems at health facility, $49(12 \%)$ mothers reported as long time admission process, 44 $(10.3 \%)$ lack of supplies and $32(7.8 \%)$ and staff work load were reasons delays at health facility level.

\section{CONCLUSION}

Mothers were not getting emergency obstetric care services in timely. Mother's literacy status, monthly income, decision making and employment status were the main predictors for maternal delays in utilization of Emergency Obstetric care service. Hence, emphasis should be given for awareness creation, income generating mechanism and decision making power of mothers; the transportation mechanisms like the ambulance service should be strengthened.

\section{ACKNOWLEDGEMENTS}

We would like to thank Bahir Dar University and GAMBY College of Medical Sciences. We are also grateful for the cooperation of the study participants.

\section{REFERENCES}

[1] United Nations Population Fund (2012) Skilled attendance at birth. http://www.unfpa.org/public/mothers/pid/4383

[2] The World Bank (2012) Over 99 percent of maternal deaths occur in developing countries. The World Bank, Washington DC.

[3] World Health Organization (2007) International statistical classification of diseases and related health problems. 10th Edition, World Health Organization, Geneva.
[4] Killewo, J., Anwar, I. Bashir, I., et al. (2006) Perceived delay in healthcare-seeking for episodes of serious illness and its implications for safe motherhood interventions in rural Bangladesh. Journal of Health, Population and $\mathrm{Nu}$ trition, 24, 403-412.

[5] Thaddeus, S. and Maine, D. (1994) Too far to walk: Maternal mortality in context. Social Science \& Medicine, 56, 1091-109. doi:10.1016/0277-9536(94)90226-7

[6] UNFPA (2012) Emergency obstetric care: Reducing lifethreatening delay. http://www.unfpa.org/public/home/mothers/pid/4385

[7] United Nations (2006) The millenium development goals report 2006. United Nations, New York.

[8] Central Statistical Agency [Ethiopia] and ICF International (2012) Ethiopia demographic and health survey 2011. Central Statistical Agency and ICF International, Addis Ababa, Ethiopia and Calverton, Maryland, USA.

[9] Odogwu, K., Audu, O., et al. (2010) Availability and utilization of emergency obstetric care services in three communities in Kaduna State, Northern Nigeria. African Journal of Reproductive Health, 14, 83-88.

[10] Cham, M., Sundby, J. and Vangen, S. (2005) Maternal mortality in the rural Gambia, a qualitative study on access to emergency obstetric care. Reproductive Health, 2, 3.

[11] Fotso, J., Ezeh, A. and Essendi, H. (2009) Maternal health in resource-poor urban settings: How does women's autonomy influence the utilization of obstetric care services? Reproductive Health, 6, 9. doi:10.1186/1742-4755-6-9

[12] Tabatabaie, M.G., et al. (2012) Home birth and barriers to referring women with obstetric complications to hospitals: A mixed methods study in Zahedan, southeastern Iran. Reproductive Health, 9, 5. doi:10.1186/1742-4755-9-5

[13] Okour, A.M., Khade, Y., Amarin, Z., et al. (2012) Maternal mortality in Jordan: Role of substandard care and delays. EMHJ, 18, 426-431.

[14] Kululanga, et al. (2011) Striving to promote male involvement in maternal health care in rural and urban set- 
tings in Malawi-A qualitative study. Reproductive Health, 8, 36. doi:10.1186/1742-4755-8-36

[15] Ochako, et al. (2011) Utilization of maternal health services among young women in Kenya: Insights from the Kenya demographic and health survey, 2003. BMC Pregnancy and Childbirth, 11, 1 doi:10.1186/1471-2393-11-1

[16] Nahar, S., Banu, M. and Nasreen, H.E. (2011) Womenfocused development intervention reduces delays in ac- cessing emergency obstetric care in urban slums in Bangladesh: A cross-sectional study. BMC Pregnancy and Childbirth, 11, 11. doi:10.1186/1471-2393-11-11

[17] Kawuwa, M.B., Mairiga, A.G. and Usman, H.A. (2007) Community perspective of maternal mortality: Experience from Konduga local government area, Borno State, Nigeria. Annals of African Medicine, 6, 109-114. doi:10.4103/1596-3519.55724

\section{LIST OF ABBREVIATIONS}

ANC: Antenatal Care;

AOR: Adjusted Odds Ratio;

ETB: Ethiopian Birr;

EOC: Emergency Obstetric Care;

OR: Odds Ratio;

SPSS: Statistical Package for Social Sciences;

SVD: Spontaneous Vaginal Delivery;

NSVD: None Spontaneous Vaginal Delivery. 